Yüzüncü Yil Üniversitesi
Tarim Bilimleri Dergisi

Araştırma Makalesi (Research Article)

\title{
Kısıntılı Sulamanın Pamuğun (G. hirsutum L.) Bazı Morfolojik Özelliklerine Etkilerinin Belirlenmesi
}

\author{
Remzi EKİNCI ${ }^{*}$, Sema BAŞBAĞ $\breve{G}^{1}$ \\ ${ }^{1}$ Dicle Üniversitesi, Ziraat Fakültesi, Tarla Bitkileri Bölümü, 21110, Diyarbakır, Türkiye \\ *Sorumlu yazar e-posta: remzi.ekinci@dicle.edu.tr
}

\begin{abstract}
Makale Bilgileri
Geliş: 18.09 .2019

Kabul: 17.12.2019

\section{Anahtar kelimeler \\ Kisintıli Sulama, \\ Morfoloji, \\ Pamuk, \\ Pamuk kütlü verimi.}

Online Yayinlanma 31.12.2019

DOI: $10.29133 /$ yyutbd.621589
Öz: Farklı tarla kapasitesi doygunluk derecelerinin (TKDD), pamuk çeşitlerinde bazı morfolojik özelliklere etkilerinin incelendiği bu çalışma, Dicle Üniversitesi Ziraat Fakültesi deneme alanında 2014-2015 yıllarında tesadüf bloklarında bölünmüş parseller deneme desenine göre 3 tekrarlamalı olarak yürütülmüştür. Ana parseller, farklı tarla kapasitesi doygunluk derecelerini (TKDD) (\% 100, $\% 80, \% 60, \% 40$ ) alt parseller ise pamuk çeşitlerini (Stoneville-453, GW-Teks ve Deltaopal) oluşturmuştur. Çalışmada bitki boyu $(\mathrm{cm})$, gövde çapı $(\mathrm{cm})$, ana kök uzunluğu (cm), yaprak alan indeksi, boy/nod oranı ve pamuk kütlü verimi $(\mathrm{kg} / \mathrm{da})$ özellikleri incelenmiştir. 2014-2015 yılları ortalamasına göre pamuk çeşitlerinin ana kök uzunluğu değerleri, $40.25 \mathrm{~cm}$ (GW-Teks) ile $43.52 \mathrm{~cm}$ (Stoneville-453) arasında; farklı TKDD uygulamalarında ana kök uzunluğu değerleri, $31.15 \mathrm{~cm}$ (\%100) ile $49.59 \mathrm{~cm}(\% 20)$ arasında değişim göstermiştir. Pamuk kütlü verimi yönünden çeşitler, $301.42 \mathrm{~kg} / \mathrm{da}$ (GW-Teks) ile $335.71 \mathrm{~kg} / \mathrm{da}$ (Stoneville-453) arasında; farklı TKDD uygulamaları ise $146.04 \mathrm{~kg} / \mathrm{da}(\% 20)$ ile $506.38 \mathrm{~kg} / \mathrm{da}$ (\%80) arasında değişmiştir. Kuraklık stresi koşulları ile ana kök uzunluğu özelliği arasında negatif korelasyon; bitki boyu, boy/nod oranı, gövde çapı, yaprak alan indeksi özellikleri arasında ise pozitif korelasyon saptanmıştır.

\section{Determination of Effects of Deficit Irrigation on Some Morphological Properties of Cotton (G. hirsutum L.)}

\section{Article Info}

Received: 18.09.2019

Accepted: 17.12.2019

Online Published 31.12.2019

DOI: $10.29133 /$ yyutbd.621589

\section{Keywords}

Restricted irrigation,

Morphological,

Cotton,

Seed cotton yield.

\begin{abstract}
This study was conducted to investigate the effects of different field capacity saturation degrees (FCSD) on some morphological characteristics of cotton varieties. The experiment was established as split-plot in RCBD with three replications at Dicle University Faculty of Agriculture in 2014-2015. The main parcels, FCSD $(100 \%, 80 \%, 60 \%$, and $40 \%)$ and the sub parcels were cotton varieties (Stoneville-453, GW-Teks, and Deltaopal). In the study, the traits such as plant height $(\mathrm{cm})$, stem diameter $(\mathrm{cm})$, root length $(\mathrm{cm})$, leaf area index, and height/nod ratio and cotton seed yield $\left(\mathrm{kg}^{-d a^{-1}}\right)$ were investigated. According to the average of 2014-2015, the main root length values of cotton varieties were between $40.25 \mathrm{~cm}$ (GW-Teks) and $43.52 \mathrm{~cm}$ (Stoneville-453); the main root length values of different FCSD applications ranged from $31.15 \mathrm{~cm}(100 \%)$ to $49.59 \mathrm{~cm}(20 \%)$. Cotton varieties in terms of cotton seed yield were changed between $301.42 \mathrm{~kg} \cdot \mathrm{da}^{-1}$ (GW-Teks) and $335.71 \mathrm{~kg}^{-\mathrm{da}^{-1}}$ (Stoneville-453); in different FCSD applications, ranged from $146.04 \mathrm{~kg} \mathrm{da}^{-1}(20 \%)$ to $506.38 \mathrm{~kg}$. da${ }^{1}(80 \%)$ Negative correlation was found between drought stress conditions and main root length trait; positive correlation was found between traits such as plant height, height/nod ratio, stem diameter, leaf area index.
\end{abstract}




\section{Giriş}

Pamuk bitkisi, yaygın ve zorunlu kullanım alanıyla insanlık açısından yarattığı katma değer ve istihdam olanaklarıyla da üretici ülkeler açısından ekonomik öneme sahip bir üründür. İklim değişimi ile birlikte son yıllarda dünya genelinde yağış miktarında bir azalma ve düzensizliğin olduğu görülmektedir. $\mathrm{Bu}$ durum, pamuk üretiminde kuraklığın gelecekte büyük sorun oluşturacağını göstermektedir. Türkiye'nin birçok bölgesinde son yıllarda kuraklaşma eğiliminin arttığ ve ilerde daha şiddetli ve uzun süreli kuraklık olaylarının görülmesi ihtimalinin yüksek olduğu bildirilmiştir (Topçu ve ark., 2012). Küresel iklim değişiminin etkisi ile iklim kuşaklarının kayacağı, Türkiye'nin, bugün Orta Doğu'da ve Kuzey Afrika'da egemen olan daha sıcak ve kurak bir iklim kuşağının etkisinde kalacağı, bu iklim kuşaklarına uyum gösteremeyen fauna ve floranın yok olacağı, bu değişim ile tarımsal ürün deseninin değişeceği öngörülmektedir (Türkeş ve ark., 2000). 2100 yılına kadar dünyanın sıcaklığının $4{ }^{\circ} \mathrm{C}$ artacağ 1 ; Türkiye ve çevresindeki bazı iç kısımlarda ise bu artış $8-9{ }^{\circ} \mathrm{C}$ kadar çıkabileceği belirtilmektedir (Tarakçığlu, 2008).

Toprak ve iklim özellikleri yönünden büyük bir tarımsal potansiyele sahip olan GAP Bölgesi'nde pamuk, büyük bir öneme sahiptir. Pamuğun yetişme mevsiminde yağışın yetersiz olması, verim artışı için sulamayı gerekli kılmaktadır. Bölgede sulanan alanların artmasına paralel olarak sulama suyu miktarının bu oranda artmaması, sulama suyunun rantabl-verimli bir şekilde kullanılmaması, global iklim değişimi ile bölge ikliminin yağış rejiminde ve toplam yağış miktarında oluşan azalışlar gibi problemler, kuraklık ve su sıkıntısını tarımsal üretimde ana problem haline getirmiştir. Kuraklık stresi tüm tarımsal ürünlerin üretimini ciddi bir şekilde etkilemektedir. Pamuk bitkisi genellikle sulanan koşullarda yetişen yazlık bir bitki olup, bölgemizde yetişme periyodu süresince ortalama $600-700 \mathrm{~mm}$ su tüketmekte, Harran ovası gibi daha sıcak bölgelerde ise su tüketimi 1000-1100 mm'ye kadar yükselmektedir.

Küresel ısınma ve buna bağlı olarak oluşan kuraklık stresi hem ülkemizde hem de dünyada pamuk tarımını olumsuz etkilemektedir. Dünya topraklarının 1/3'ünden fazlasını yakından ilgilendiren kuraklık stresi, tarımsal ürünlerinin üretiminde ciddi sorunlara neden olmaktadır (Monti, 1987). Bu nedenle kuraklık stresinin pamuk bitkisinin ekolojisinde, morfolojisinde nasıl bir değişim meydana getirdiğinin araştırılması, kuraklıkla oluşan zararın boyutlarının anlaşılması ve ileride daha da artacağı belirtilen zararlarının önlenmesi için tedbirlerin alınması yönünden önem taşımaktadır. Yapılan araştırmalar bitki su stresinin, kolaylıkla ölçülebilen parametreler kullanılarak niceliksel olarak ifade edilebileceğini göstermiştir. Söz konusu parametreler, bitki taç ve hava sıcaklığı farkı ile yaygın olarak atmosferin buharlaştırma istemi olarak tanımlanan havanın buhar basıncı açığıdır (Jackson, 1982; Idso ve ark., 1977). Bu çalışma, pamuk bitkisinin üretiminde yaşanan su kısıntılarında üretimin daha az etkilenmesine yönelik olarak bilimsel ve pratik uygulamalara katkı sağlamak amacıyla yapılmıştır.

\section{Materyal ve Yöntem}

Çalışma, Dicle Üniversitesi Ziraat Fakültesi deneme alanında 2014-2015 yıllarında bölünmüş parseller deneme desenine göre 3 tekrarlamalı olarak yürütülmüştür. Ana parselleri, farklı tarla kapasitesi doygunluk derecesi (TKDD, \%) (\%100, \%80, \%60, \%40), alt parselleri ise pamuk çeşitleri (Stoneville-453, GW-Teks ve Deltaopal) oluşturmuştur.

Diyarbakır'ın iklimsel faktörleri incelendiğinde sert bir kara ikliminin egemen olduğu görülmektedir. Yazları çok sıcak, kışları ise şiddetli soğuktur. En sıcak ay ortalaması $31^{\circ} \mathrm{C}$, en soğuk ay ortalaması ise $1.8^{\circ} \mathrm{C}$ 'dir. $486.7 \mathrm{~mm}$ olan yıllık ortalama yăğş miktarının yaklaşık \%2'si yaz aylarında düşmekte ve kuzeye doğru gidildikçe yağış miktarı artmaktadır. Ortalama nispi nem en çok (\%77) Aralık ve Ocak aylarında en az (\%20) ise Temmuz-Ağustos aylarında oluşmaktadır (Anonim, 2015).

Deneme alanı topraklarının fiziksel (bünye analizi, volüm ağırlığ $\left(\mathrm{gr} / \mathrm{cm}^{3}\right)$, tarla kapasitesi ve devamlı solma noktası) ve kimyasal ( $\mathrm{pH}$, \% kireç) özellikleri, 0-90 derinliklerden alınan örneklerde, Tüzüner (1990) tarafindan belirtilen analiz yöntemleriyle belirlenmiştir. Ayrıca bitki boyu (cm), gövde çapı $(\mathrm{cm})$, ana kök uzunluğu $(\mathrm{cm})$ ölçülmüş, yaprak alan indeksi (Sunscan cihazı ile), boy/nod oranı ve pamuk kütlü verimi $(\mathrm{kg} / \mathrm{da})$ özellikleri belirlenmiştir. 
İlk sulama öncesi toprak su içeriği tespiti için her parselin orta 2 sıra arasına Delta T Profile Probe cihazına ait $90 \mathrm{~cm}$ 'lik probe tüpü yerleştirilmiştir. Deneme yerini temsil eden bir noktadan profil çukuru açılarak, 30'ar cm'lik katmanlar halinde $90 \mathrm{~cm}$ 'ye kadar bozulmuş ve bozulmamış toprak örnekleri alınmıştır. Toprak örneklerinde, Tüzüner (1990) tarafından belirtilen analiz yöntemleri kullanılarak; tarla kapasitesi, devamlı solma noktası, volüm ağırlığı ve toprak bünyesi gibi fiziksel analizler ile toprak reaksiyonu, toplam tuz, organik madde, kireç, yararlanılabilir fosfor ve potasyum kimyasal analizler yapılmıştır. Deneme yerinden 0-90 cm derinliklerden toprak numuneleri alınarak, analiz edilmiştir. Bünye sınıfı killi-tınlı, su ile doygunluk \%62, tarla kapasitesi (TK) \%41.52, solma noktası (SN) \%11.88, volüm ağırlı̆̆ $1.35 \mathrm{gr} / \mathrm{cm}^{3}, \mathrm{pH}$ 7.87, iletkenlik $1.064 \mathrm{dS} / \mathrm{m}$, kireç içeriği \%30.4, fosfor içeriği \%4.4, potasyum içeriği $\% 1.25$ ve organik madde miktarının $\% 1.8$ düzeyinde saptanmıştır.

Deneme alanına $16 \mathrm{~kg} / \mathrm{da} \mathrm{N}, 7 \mathrm{~kg} / \mathrm{da}_{2} \mathrm{O}_{5}$ gübrelemesi yapılmıştır. Sulamalarda damla sulama yöntemi kullanılmıştır. İlk sulamada, tüm parseller toprak tarla kapasitesine getirilecek düzeyde sulama yapılmıştır. Sulamalarda ana parsellere, toprak profilinin $90 \mathrm{~cm}$ derinliğindeki eksik nemi tarla kapasitesine getirmek için gerekli sulama suyu miktarının sayaç ile verilmesi planlanmıştır. Sulamaya topraktaki elverişli nem \%35'e düştüğünde başlanılmıştır. Bitki su tüketimi, su dengesi eşitliğine dayanan "Nem Azalma Yöntemi", ile hesaplanmıştır (Beyce ve ark., 1972). Tüm parsellerde Delta T Profile Probe cihazı ile sulama öncesi ve sulama sonrası toprak suyu ölçümleri yapmıştır.

Çalışmada, her bir özellik için elde edilen değerler, JMP 5.0 (Copyright (C) 1989-2002 SAS Institute Inc.) istatistik paket programı kullanılarak, istatistiksel yönden analiz edilmiştir. Sonuçlar, F testi, korelasyon ve regresyon analizleri ile incelenmiş ve ortalamalar, EGF testi uyarınca gruplandırılmıştır.

\section{Bulgular ve Tartışma}

İncelenen özelliklerden bitki boyu, gövde çapı ve ana kök uzunluğuna ait ortalama değerler Çizelge 1'de, yaprak alanı indeksi, boy/nod oranı ve pamuk kütlü verimine ait ortalama değerler ise Çizelge 2'de verilmiştir.

Bitki boyu (cm): Çalışmada kullanılan pamuk çeşitlerinin, farklı TKDD uygulamalarında bitki boyu yönünden, Çeşit ve TKDD uygulamaları \%1 düzeyinde önemli bulunmuştur. Pamuk çeşitlerinin bitki boyları $82.63 \mathrm{~cm}$ (Stoneville-453) ile $94.34 \mathrm{~cm}$ (GW-Teks) arasında değişim göstermiş; farklı TKDD uygulamalarında bitki boyu değerleri, $70.26 \mathrm{~cm}(\% 20)$ ile $117.48 \mathrm{~cm}(\% 80)$ arasında değişim göstermiştir. \%80 TKDD uygulamas1, en uzun bitki boyunun elde edildiği grubu oluştururken, \%20 TKDD uygulamasının ise en kısa bitki boyu grubunu oluşturduğu Çizelge 1'de görülebilmektedir. ElZik ve Thaxton (1989), kuraklığa dayanıklılık bakımından çeşitler arasında önemli farklılıkların olabileceğini bildirmiştir. Bütün çeşitlerde bitki boyunun farklı TKDD uygulamalarından oldukça etkilendiği, materyali oluşturan her 3 pamuk çeşidinde TKDD uygulamaları ile bitki boyu özelliği arasında quatratik bir ilişki belirlenmiştir. Tüm çeşitler dikkate alındığında $\mathrm{y}=-0.0135 \mathrm{x}^{2}+2.4815 \mathrm{x}-$ $6.8585\left(\mathrm{R}^{2}=0.60\right)$ değişim denkleminin elde edildiği, en uzun bitki boyunun elde edildiği TKDD uygulamasının \%91 olduğu; en yüksek bitki boyu değerinin ise $107.18 \mathrm{~cm}$ olduğu saptanmıştır (Şekil 2). Pamuk bitkisi gelişiminde su oldukça önemli bir yer tutmaktadır. Kurak koşullarda pamuk bitkisinin gelişimi yavaşladığ 1 için boyu kısa kalmaktadır.

Gövde çapı (cm): Çalışmada kullanılan pamuk çeşitlerinin, farklı TKDD uygulamalarında gövde çapı yönünden, Çeşit, TKDD uygulamaları ve ÇeşitxTKDD interaksiyonunun \%1 düzeyinde önemli olduğu Çizelge 1'de görülebilmektedir. Farklı pamuk çeşitlerinin gövde çapı değerleri, $2.63 \mathrm{~cm}$ (Stoneville-453) ile $3.10 \mathrm{~cm}$ (Deltaopal) arasında; farklı TKDD uygulamalarında gövde çapı değerleri ise $2.18 \mathrm{~cm}(\% 20)$ ile $3.80 \mathrm{~cm}(\% 80)$ arasında değişmiştir. \%80 TKDD uygulamasının en yüksek gövde çapı değerine; \%20 TKDD uygulamasının ise en düşük gövde çapı değerine sahip olduğu belirlenmiştir (Çizelge 1). Her 3 pamuk çeşidinde de TKDD uygulamaları ile gövde çapı özelliği arasında pozitif ve quatratik bir ilişkinin, var olduğu görülmektedir. Tüm çeşitler dikkate alındığında $y=$ $0.0005 \mathrm{x}^{2}+0.0877 \mathrm{x}-0.1741\left(\mathrm{R}^{2}=0.30\right)$ değişim denkleminin elde edildiği, en yüksek gövde çapı değerinin elde edildiği TKDD değerinin, \%87.70 olduğu saptanmıştır (Şekil 3). Davies ve Zhang (1991), ve Naqvi (1995) kuraklık stresinin hormonal dengenin bozulmasına yol açtığını ve gövde -kök gelişiminin ters yönlü etkilediğini bildirmişlerdir.

Yaprak alanı indeksi (LAI): Çalışmada kullanılan pamuk çeşitlerinin, farklı TKDD uygulamalarına göre yaprak alan indeksi özelliği yönünden, Çeşit, TKDD uygulamaları ve yıl varyasyon 
kaynaklarının birbirinden \%1 düzeyinde önemli farklılık gösterdiği Çizelge 2'de görülebilmektedir. Farklı pamuk çeşitlerinin yaprak alan indeksi değerlerinin, 3.23 (Stoneville-453) ile 3.98 (GW-Teks) arasında değişim göstermiş; GW-Teks çeşidi en yüksek; Stoneville-453 çeşidi ise en düşük yaprak alan indeksi değerini almıştır. Farklı TKDD uygulamalarında yaprak alan indeksinin ise 2.08 (\%20) ile 6.36 (\%80) arasında değişim gösterdiği belirlenmiştir (Çizelge 2).

Bütün çeşitlerde yaprak alan indeksi değerlerinin farklı TKDD uygulamalarından oldukça etkilendiği, her 3 pamuk çeşidinde de TKDD uygulamaları ile yaprak alan indeksi özelliği arasında quatratik bir ilişkinin, var olduğu görülmektedir. TKDD ile yaprak alan indeksi arasında pozitif ikili ilişkinin $(\mathrm{r}=+0.70, \mathrm{p}<0.001)$ saptanması bu sonucu desteklemektedir. Çeşitler dikkate alındığında $\mathrm{y}=-$ $0.0014 \mathrm{x}^{2}+0.2557 \mathrm{x}-6.0717\left(\mathrm{R}^{2}=0.60\right)$ değişim denkleminin elde edildiği, en yüksek yaprak alan indeksi değerinin elde edildiği TKDD uygulamasının \%91 olduğu; en yüksek yaprak alan indeksi değerinin ise 5.60 olduğu saptanmıştır (Şekil 4). Yaprak alan indeksi pamuk bitkisinin gelişimi ve fizyolojik dengesinin bir göstergesi olarak kuraklık stresinden olumsuz etkilendiği saptanmıştır (Radin ve ark., 1992). Gerek çeşitler arasında ve gerekse kuraklık stresi koşullarının yaprak alan indeksinde önemli farklılık oluşturması, bu özelliğin diğer stres çalışmalarında güven ile kullanılabileceğini ortaya koymaktadır.

Boy/nod oranı: Çalışmada kullanılan pamuk çeşitlerinin, boy/nod oranı özelliği yönünden, Çeşit ve TKDD uygulamalarının \%1 düzeyinde önemli olduğu saptanmıştır. Pamuk çeşitlerinin boy/nod oranı değerleri, 2.64 (GW-Teks) ile 3.01 (Stoneville-453) arasında değişim göstermiştir. TKDD uygulamalarının boy/nod oranı değerleri ise $2.04(\% 20)$ ile $3.92{ }^{\circ} \mathrm{C}(\% 100)$ arasında belirlenmiştir. \%100 TKDD uygulamasında en yüksek, \%20 TKDD uygulamasından ise en düşük boy/nod oranı elde edilmiştir (Çizelge 2). Bütün çeşitlerde boy/nod oranı değerlerinin farklı TKDD uygulamalarından oldukça etkilendiği, her 3 pamuk çeşidinde de TKDD uygulamaları ile boy/nod oranı özelliği arasında linear bir ilişkinin, var olduğu görülmektedir. TKDD ile boy/nod oranı arasında pozitif ikili ilişkinin $(\mathrm{r}=+0.93, \mathrm{p}<0.001)$ saptanması, linear ilişkiyi desteklemektedir. Tüm çeşitler dikkate alındığında $\mathrm{y}=0.0297 \mathrm{x}+0.9731\left(\mathrm{R}^{2}=0.88\right)$ değişim denkleminin elde edildiği, Şekil 5'den görülebilmektedir. Pamuk bitkisi gelişiminde bitki boyu ve nod oluşumları, birbiri ile oldukça ilişkili iki gelişim unsurudur. Boy/nod oranındaki düşüş, bitki büyüme ve gelişimi ile benzerlik gösterdiği gibi, verim düşüşü ile benzerlik göstermiştir. Bulgularımız, Heitholt (1994), Kerby ve ark., (2010 ve Ekinci (2017) bulguları ile benzerlik göstermektedir. Kuraklığın varlığı ve şiddetinin belirlenmesinde boy/nod oranı parametresi rahatlıkla kullanılabileceği saptanmıştır.

Ana kök uzunluğu (cm): Çalışmada kullanılan pamuk çeşitlerinin, farklı TKDD uygulamalarına göre ana kök uzunluğu özelliği yönünden, çeşit, TKDD ve Yıl varyasyon kaynakları \%1 düzeyinde önemli olduğu belirlenmiştir. Farklı pamuk çeşitlerinin ana kök uzunluğu değerleri, $40.25 \mathrm{~cm}(\mathrm{GW}$ Teks) ile $43.52 \mathrm{~cm}$ (Stoneville-453) arasında değişim göstermiştir. TKDD uygulamalarının ana kök uzunluğu değerleri ise $31.15 \mathrm{~cm}(\% 100)$ ile $49.59 \mathrm{~cm}(\% 20)$ arasında saptanmıştır. GW-Teks ve Deltaopal çeşitleri en kısa; Stoneville-453 çeşidi ise en uzun grupta yer almıştır. \%20 TKDD uygulaması, en yüksek; \%100 TKDD uygulaması ise en düşük ana kök uzunluğu grubunu oluşturmuştur (Çizelge 1). Bütün çeşitlerde ana kök uzunluğu değerlerinin farklı TKDD uygulamalarından oldukça etkilendiği, her 3 pamuk çeşidinde de TKDD uygulamaları ile ana kök uzunluğu arasında linear bir ilişkinin, var olduğu saptanmıştır. TKDD uygulamaları ile ana kök uzunluğu özelliği arasında negatif ikili ilişki $(\mathrm{r}=-0.90, \mathrm{p}<0.001)$ saptanması, linear ilişkiyi destekler niteliktedir. Tüm çeşitler dikkate alındığında $\mathrm{y}=-0.3042 \mathrm{x}+60.802\left(\mathrm{R}^{2}=0.81\right)$ değişim denklemi elde edilmiştir (Şekil 6).

Pamuk bitkisinin ana kök gelişimi bitkinin kurak koşullarda toprak nemine ulaşabilmesi için daha hızlı geliştiğinin göstergesidir (Kaçar, 2007). İlk sulama suyunun geciktirilmesi ile bitkinin ana kök gelişiminin arttığı belirlenmiştir. Çalışmada elde ettiğimiz bulgular, Quisenberry ve ark., (1982), Benedict (1984), Ramamoorthy ve ark., (2017), Niu ve ark., (2018), Singh ve ark., (2018), Bat ve ark., (2019), Hasan ve ark., (2019) ve Chen ve ark., (2019) kök morfolojisi ve büyüme potansiyelinin, su stresi koşullarında önemli bir faktör olduğu konusundaki bulgularının destekler niteliktedir.

Pamuk kütlü verimi $(\mathrm{kg} / \mathrm{da})$ : Çalışmada kullanılan pamuk çeşitleri ve farklı TKDD uygulamaları kütlü pamuk verimi yönünden \%1 düzeyinde önemli bulunmuştur. Farklı pamuk çeşitlerinin kütlü verimleri, $301.42 \mathrm{~kg} / \mathrm{da}$ (GW-Teks) ile $335.71 \mathrm{~kg} / \mathrm{da}$ (Stoneville-453) arasında meydana gelmiştir. TKDD uygulamaları pamuk kütlü verimleri ise $146.04 \mathrm{~kg} / \mathrm{da}(\% 20)$ ile $506.38 \mathrm{~kg} / \mathrm{da}(\% 80)$ arasında değişim göstermiştir. Stoneville-453 çeşidi $(335.71 \mathrm{~kg} / \mathrm{da})$ pamuk kütlü verimi yönünden en yüksek grupta yer alırken, GW-Teks (301.42 kg/da) ve Deltaopal $(316.16 \mathrm{~kg} / \mathrm{da})$ çeşitleri daha düşük grupta yer 
almıştır. \%80 TKDD uygulaması (506.38 kg/da) en yüksek pamuk kütlü veriminin elde edildiği grubu, $\% 20(146.04 \mathrm{~kg} / \mathrm{da})$ ve $\% 40$ TKDD uygulamaları $(164.02 \mathrm{~kg} / \mathrm{da})$ ise en düşük pamuk kütlü veriminin elde edildiği grubu oluşturmuştur (Çizelge 2).

Bütün çeşitlerde pamuk kütlü verim değerlerinin farklı TKDD uygulamalarından oldukça etkilendiği ve her 3 pamuk çeşidinde TKDD uygulamaları ile pamuk kütlü verim özelliği arasında quatratik bir ilişkinin, var olduğu görülmektedir. TKDD ile pamuk kütlü verim özelliği arasında pozitif ikili ilişki $(\mathrm{r}=+0.84, \mathrm{p}<0.001)$ saptanması quatratik ilişkiyi desteklemektedir. Çeşitlerin tamamı dikkate alındığında $\mathrm{y}=-0.1472 \mathrm{x}^{2}+25.739 \mathrm{x}-645.11\left(\mathrm{R}^{2}=0.91\right)$ değişim denkleminin elde edildiği, en yüksek pamuk kütlü veriminin TKDD değerinin, \%87 olduğu saptanmıştır (Şekil 7).

Pamuk bitkisi gelişiminde su oldukça önemli bir faktör olup, kuraklık (yetersiz toprak nemi) koşullarında, yaprak alan indeksinde (Gerik ve ark., 1996; Pettigrew, 2004; Awasthi ve ark., 2018); gelişim ve büyümesinde (Snowden ve ark.,. 2013; Wang ve ark., 2016; Ullah ve ark., 2017; Lei ve ark., 2018; İbrahim ve ark., 2019) verim ve verim unsurlarında ciddi bir şekilde düşüşlere neden olmaktadır (Pettigrew, 2004; Hussein ve ark., 2011; Cave, 2013; Niu ve ark., 2018; Bahramloo ve Nasseri, 2019). Ayrıca, aşırı sulama (yüksek toprak nemi) koşullarında da bitki strese girerek gelişimini yavaşlatmaktadır. $\mathrm{Bu}$ durum, pamuğun gelişim ve büyümesinde, pamuk kütlü verimi ve verim öğelerinin olumsuz etkilenmesine neden olmaktadır.

\section{Sonuç}

Kuraklık stresinin diğer birçok bitkide olduğu gibi pamuk bitkisinde de incelenen özellikler yönünden olumsuz etkileri belirlenmiş, kuraklık stres koşulları ile bitki boyu, gövde çapı, yaprak alan indeksi özellikleri arasında quatratik; ana kök uzunluğu, boy/nod oranı özellikleri arasında ise linear bir ilişkinin var olduğu saptanmıştır. Kuraklık stresi koşulları ile ana kök uzunluğu özelliği arasında negatif korelasyon; bitki boyu, boy/nod oranı, gövde çapı, yaprak alan indeksi özellikleri arasında pozitif korelasyon tespit edilmiştir. En uygun TKDD değerinin bitki boyu özelliği için \%84, gövde çap1, özelliği için \%87, yaprak alan indeksi özelliği için, \%91 olduğu sonuçlarına varılmıştır. Genotiplerin kuraklık stresi koşullarında performanslarının belirlenmesine yönelik olarak yapılacak çalışmalarda ana kök uzunluğu, boy/nod oranı, gövde çapı, yaprak alan indeksi parametrelerinin önemli ve pratik olması nedeniyle kullanımının önerildiğii, kurak koşullarda, verim ve verim unsurlarında ciddi düşüşler meydana gelirken aşırı sulama koşullarında da bitki strese girerek gelişimini yavaşlatmakta ve kütlü verimi ve verim unsurlarında düşüşler oluşturmaktadır.

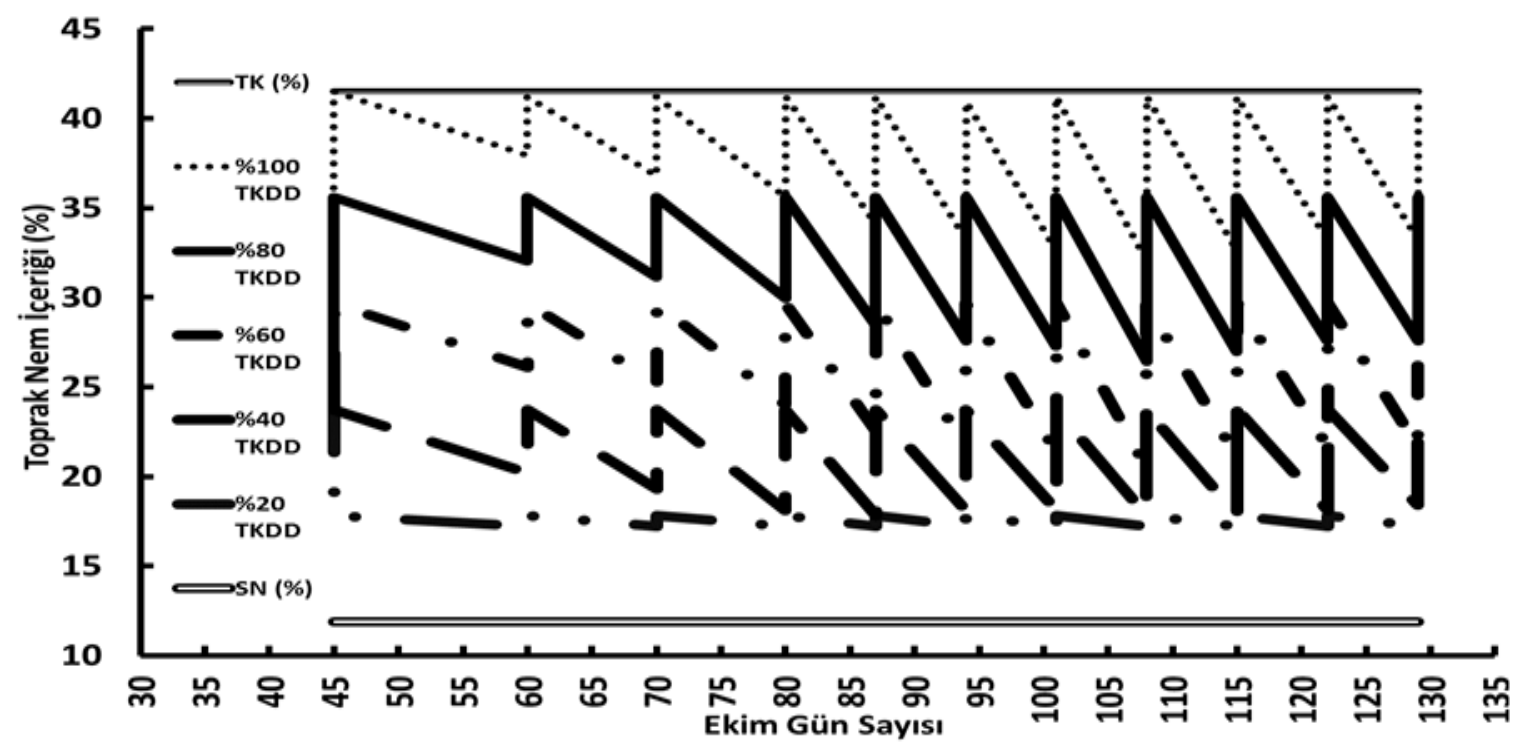

Şekil 1. Sulama öncesi ve sulama sonrası toprak nem değişimleri. 


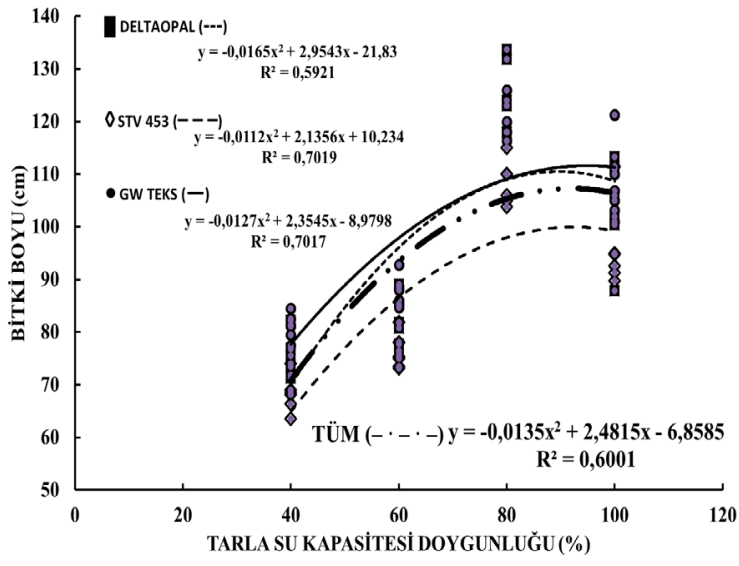

Şekil 2. TKDD’lere göre bitki boyu değiş̧imi.

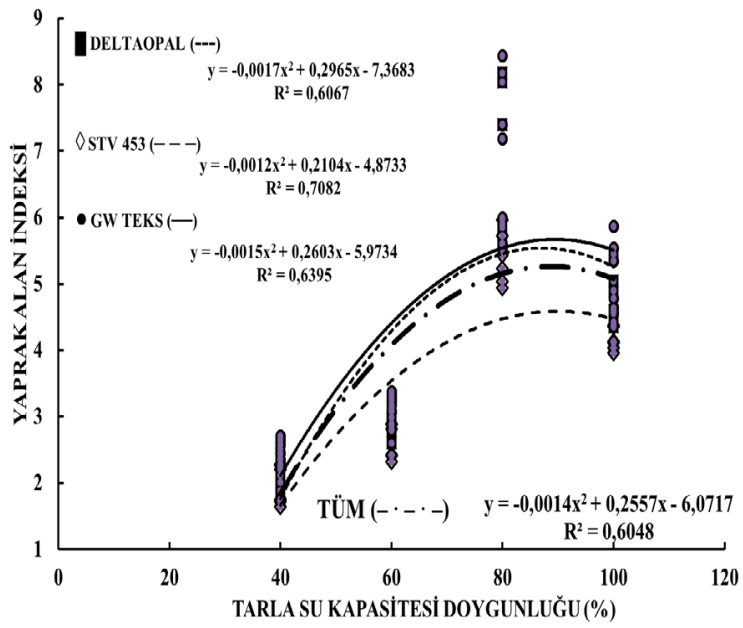

Şekil 4. TKDD’lere göre yaprak alanı indeksi değişimi.

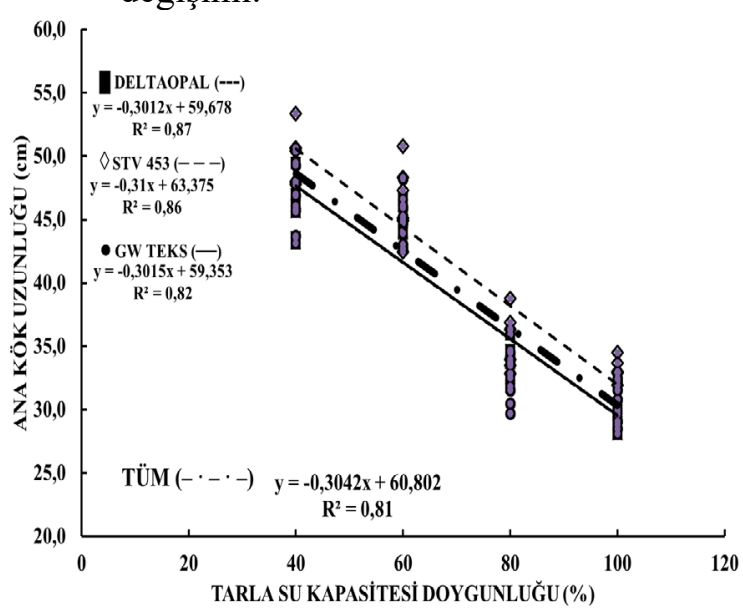

Şekil 6. TKDD’lere göre ana kök uzunluğu değişimi.

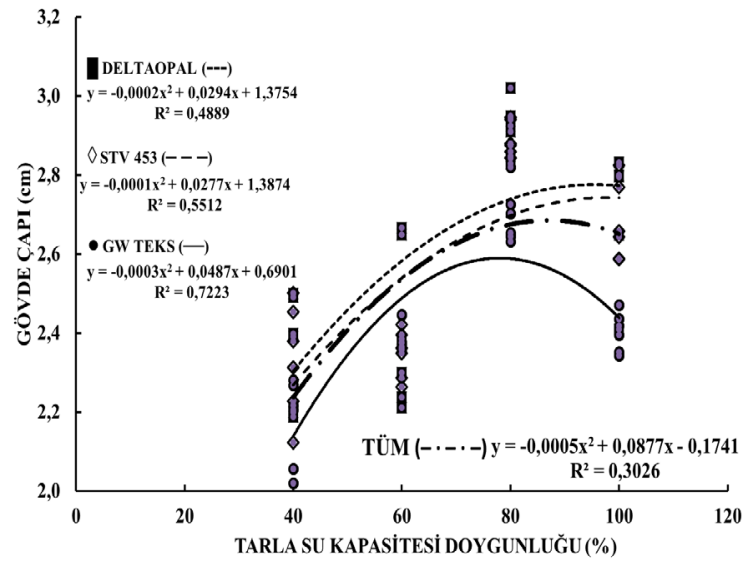

Şekil 3. TKDD’lere göre gövde çapı değişimi.

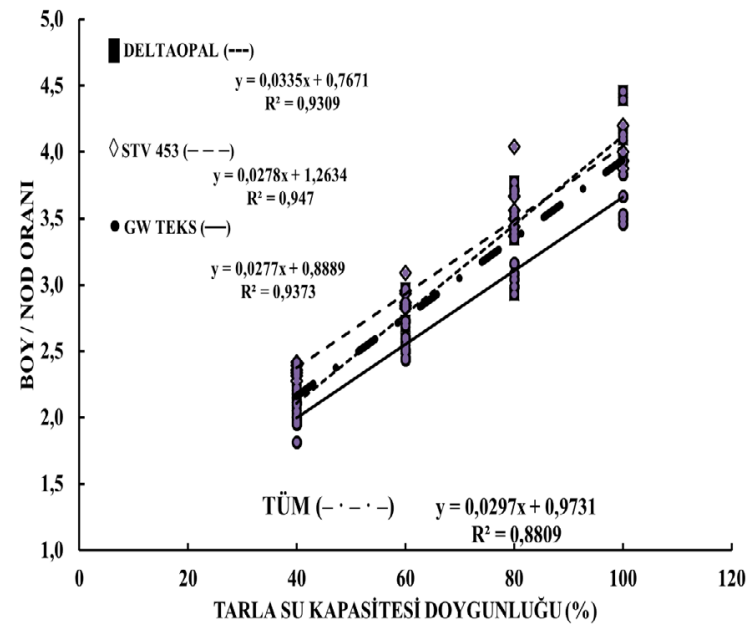

Şekil 5. TKDD'lere göre boy/nod oranı değişimi.

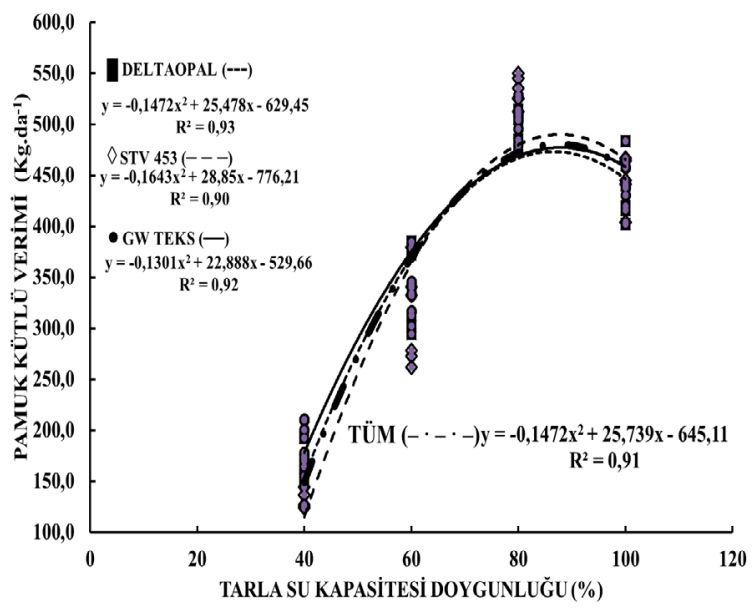

Şekil 7. TKDD’lere göre pamuk kütlü verimi değişimi.

Çizelge 1. Bitki boyu, gövde çap1 ve ana kök uzunluğuna ilişkin ortalama değerler.

\begin{tabular}{|c|c|}
\hline Cesitler & TKDD (\%) \\
\hline
\end{tabular}




\begin{tabular}{|c|c|c|c|c|c|c|c|c|c|c|c|c|}
\hline & & 2014 & 2015 & Ort. & & 2014 & 2015 & & rt. & 2014 & 2015 & Ort. \\
\hline \multirow{5}{*}{ Deltaopal } & $20 \%$ & 70.00 & 70.83 & 70.42 & & 2.35 & 2.18 & 2.27 & gh & 51.09 & 48.10 & 49.59 \\
\hline & $40 \%$ & 73.46 & 76.98 & 75.22 & & 2.64 & 2.56 & 2.60 & fgh & 47.07 & 44.59 & 45.83 \\
\hline & $60 \%$ & 80.11 & 80.44 & 80.28 & & 2.84 & 2.63 & 2.73 & efg & 46.27 & 44.02 & 45.14 \\
\hline & $80 \%$ & 121.67 & 127.86 & 124.76 & & 4.65 & 4.52 & 4.59 & $\mathrm{a}$ & 34.79 & 33.01 & 33.90 \\
\hline & $100 \%$ & 102.82 & 104.05 & 103.43 & & 3.38 & 3.23 & 3.30 & bcd & 29.97 & 29.02 & 29.50 \\
\hline \multirow{5}{*}{$\begin{array}{c}\text { Stoneville- } \\
453\end{array}$} & $20 \%$ & 64.33 & 64.91 & 64.62 & & 2.15 & 2.03 & 2.09 & $\bar{h}$ & 51.80 & 50.01 & 50.90 \\
\hline & $40 \%$ & 67.70 & 68.88 & 68.29 & & 2.42 & 2.24 & 2.33 & gh & 51.82 & 49.20 & 50.51 \\
\hline & $60 \%$ & 74.60 & 77.70 & 76.15 & & 2.46 & 2.37 & 2.42 & gh & 48.12 & 45.62 & 46.87 \\
\hline & $80 \%$ & 106.59 & 110.00 & 108.29 & & 3.29 & 3.09 & 3.19 & bcde & 36.66 & 34.92 & 35.79 \\
\hline & $100 \%$ & 93.68 & 97.90 & 95.79 & & 3.19 & 3.07 & 3.13 & cdef & 34.16 & 32.91 & 33.54 \\
\hline \multirow{5}{*}{ GW-Teks } & $20 \%$ & 76.00 & 75.47 & 75.74 & & 2.30 & 2.07 & 2.19 & $\mathrm{~h}$ & 49.42 & 47.14 & 48.28 \\
\hline & $40 \%$ & 79.45 & 82.74 & 81.09 & & 3.00 & 2.92 & 2.96 & def & 47.36 & 45.08 & 46.22 \\
\hline & $60 \%$ & 86.27 & 88.90 & 87.58 & & 2.99 & 2.94 & 2.97 & def & 45.69 & 43.53 & 44.61 \\
\hline & $80 \%$ & 120.11 & 118.67 & 119.39 & & 3.83 & 3.43 & 3.63 & $\mathrm{bc}$ & 32.45 & 31.03 & 31.74 \\
\hline & $100 \%$ & 107.27 & 108.49 & 107.88 & & 3.78 & 3.62 & 3.70 & $\mathrm{~b}$ & 30.15 & 30.68 & 30.41 \\
\hline Deltaopal & & 89.61 & 92.03 & 90.82 & $\mathrm{~b}$ & 3.17 & 3.02 & 3.10 & $\bar{a}$ & 41.84 & 39.75 & $40.79 \mathrm{~b}$ \\
\hline Stoneville-453 & & 81.38 & 83.88 & 82.63 & $\mathrm{c}$ & 2.70 & 2.56 & 2.63 & $b$ & 44.51 & 42.53 & $43.52 \mathrm{a}$ \\
\hline GW-Teks & & 93.82 & 94.85 & 94.34 & $\mathrm{a}$ & 3.18 & 2.99 & 3.09 & $\mathrm{a}$ & 41.01 & 39.49 & $40.25 \mathrm{~b}$ \\
\hline \multirow{5}{*}{ Ort. } & $20 \%$ & 70.11 & 70.40 & 70.26 & $\overline{\mathrm{e}}$ & 2.27 & 2.09 & 2.18 & $\bar{d}$ & 50.77 & 48.41 & $49.59 \mathrm{a}$ \\
\hline & $40 \%$ & 73.54 & 76.20 & 74.87 & $\mathrm{~d}$ & 2.69 & 2.57 & 2.63 & $\mathrm{c}$ & 48.75 & 46.29 & $47.52 \mathrm{~b}$ \\
\hline & $60 \%$ & 80.33 & 82.35 & 81.34 & $\mathrm{c}$ & 2.76 & 2.65 & 2.71 & $\mathrm{c}$ & 46.69 & 44.39 & $45.54 \mathrm{c}$ \\
\hline & $80 \%$ & 116.12 & 118.84 & 117.48 & $\mathrm{a}$ & 3.92 & 3.68 & 3.80 & $\mathrm{a}$ & 34.63 & 32.99 & $33.81 \mathrm{~d}$ \\
\hline & $100 \%$ & 101.26 & 103.48 & 102.37 & $\mathrm{~b}$ & 3.45 & 3.30 & 3.38 & $\mathrm{~b}$ & 31.43 & 30.87 & $31.15 \mathrm{e}$ \\
\hline Ortalama & & 88.27 & 90.25 & 89.26 & & 3.02 & 2.86 & 2.94 & & $42.45 \mathrm{a}$ & $40.59 \mathrm{~b}$ & 41.52 \\
\hline
\end{tabular}

Ort.: Ortalama; TKDD: Tarla kapasitesi su doygunluk derecesi; cm: Santimetre; Aynı harfler aynı grupları göstermektedir.

Çizelge 2. Yaprak alanı indeksi, boy/nod oranı ve pamuk kütlü verimine ilişkin ortalama değerler

\begin{tabular}{|c|c|c|c|c|c|c|c|c|c|c|c|c|}
\hline \multirow[b]{2}{*}{ Çeşitler } & \multirow{2}{*}{$\begin{array}{c}\text { TKDD } \\
(\%)\end{array}$} & \multicolumn{4}{|c|}{ Yaprak Alan İndeksi } & \multicolumn{4}{|c|}{ Boy/Nod Oranı } & \multicolumn{3}{|c|}{ Pamuk Kütlü Verimi (kg/da) } \\
\hline & & 2014 & 2015 & Ort. & & 2014 & 2015 & Or & & 2014 & 2015 & Ort. \\
\hline \multirow{5}{*}{ Deltaopal } & $20 \%$ & 2.33 & 1.82 & 2.08 & & 2.06 & 2.02 & 2.04 & gh & 147.97 & 149.88 & 148.93 \\
\hline & $40 \%$ & 2.44 & 2.01 & 2.22 & & 2.16 & 2.20 & 2.18 & fgh & 155.75 & 171.69 & 163.72 \\
\hline & $60 \%$ & 3.08 & 2.76 & 2.92 & & 2.67 & 2.68 & 2.68 & efg & 303.06 & 378.39 & 340.73 \\
\hline & $80 \%$ & 5.79 & 7.87 & 6.83 & & 3.43 & 3.47 & 3.45 & $\mathrm{a}$ & 500.90 & 480.00 & 490.45 \\
\hline & $100 \%$ & 4.46 & 5.13 & 4.80 & & 4.06 & 4.26 & 4.16 & bcd & 440.05 & 433.89 & 436.97 \\
\hline \multirow{5}{*}{$\begin{array}{l}\text { Stoneville- } \\
453\end{array}$} & $20 \%$ & 2.14 & 1.54 & 1.84 & & 2.24 & 2.16 & 2.20 & $\mathrm{~h}$ & 172.03 & 164.04 & 168.04 \\
\hline & $40 \%$ & 2.25 & 1.70 & 1.98 & & 2.34 & 2.36 & 2.35 & gh & 185.13 & 207.02 & 196.08 \\
\hline & $60 \%$ & 2.86 & 2.39 & 2.62 & & 2.88 & 2.96 & 2.92 & gh & 337.52 & 333.35 & 335.44 \\
\hline & $80 \%$ & 5.07 & 6.04 & 5.56 & & 3.58 & 3.62 & 3.60 & bcde & 542.78 & 525.00 & 533.89 \\
\hline & $100 \%$ & 4.07 & 4.26 & 4.17 & & 4.00 & 3.96 & 3.98 & cdef & 447.64 & 442.62 & 445.13 \\
\hline \multirow{5}{*}{ GW-Teks } & $20 \%$ & 2.53 & 2.15 & 2.34 & & 1.89 & 1.85 & 1.87 & $\mathrm{~h}$ & 125.74 & 116.57 & 121.16 \\
\hline & $40 \%$ & 2.65 & 2.35 & 2.50 & & 1.99 & 1.97 & 1.98 & def & 133.33 & 131.21 & 132.27 \\
\hline & $60 \%$ & 3.31 & 3.19 & 3.25 & & 2.49 & 2.59 & 2.54 & def & 270.87 & 350.88 & 310.88 \\
\hline & $80 \%$ & 5.71 & 7.68 & 6.69 & & 3.12 & 3.26 & 3.19 & bc & 507.58 & 482.04 & 494.81 \\
\hline & $100 \%$ & 4.66 & 5.59 & 5.12 & & 3.55 & 3.67 & 3.61 & $\mathrm{~b}$ & 457.33 & 438.63 & 447.98 \\
\hline \multirow{3}{*}{\multicolumn{2}{|c|}{$\begin{array}{l}\text { Deltaopal } \\
\text { Stoneville-453 } \\
\text { GW-Teks }\end{array}$}} & 3.62 & 3.92 & 3.77 & $\mathrm{~b}$ & 2.87 & 2.93 & 2.90 & $\mathrm{~b}$ & 309.55 & 322.77 & $316.16 b$ \\
\hline & & 3.28 & 3.19 & 3.23 & $\mathrm{c}$ & 3.00 & 3.01 & 3.01 & $\mathrm{a}$ & 337.02 & 334.41 & $335.71 \mathrm{a}$ \\
\hline & & 3.77 & 4.19 & 3.98 & $\mathrm{a}$ & 2.61 & 2.67 & 2.64 & $\mathrm{c}$ & 298.97 & 303.87 & $301.42 \mathrm{~b}$ \\
\hline \multirow{5}{*}{ Ort. } & $20 \%$ & 2.33 & 1.84 & 2.08 & $\mathrm{e}$ & 2.06 & 2.01 & 2.04 & $\mathrm{e}$ & 148.58 & 143.50 & $146.04 \mathrm{~d}$ \\
\hline & $40 \%$ & 2.45 & 2.02 & 2.23 & $\mathrm{~d}$ & 2.16 & 2.18 & 2.17 & d & 158.07 & 169.97 & $164.02 \mathrm{~d}$ \\
\hline & $60 \%$ & 3.08 & 2.78 & 2.93 & $\mathrm{c}$ & 2.68 & 2.74 & 2.71 & $\mathrm{c}$ & 303.82 & 354.21 & $329.01 \mathrm{c}$ \\
\hline & $80 \%$ & 5.52 & 7.20 & 6.36 & $\mathrm{a}$ & 3.37 & 3.45 & 3.41 & b & 517.09 & 495.68 & $506.38 \mathrm{a}$ \\
\hline & $100 \%$ & 4.40 & 4.99 & 4.70 & $\mathrm{~b}$ & 3.87 & 3.96 & 3.92 & $\mathrm{a}$ & 448.34 & 438.38 & $443.36 \mathrm{~b}$ \\
\hline Ortalama & & 3.56 & $3.76 \mathrm{a}$ & 3.66 & & 2.83 & 2.87 & 2.85 & & 315.18 & 320.30 & 317.76 \\
\hline
\end{tabular}

Ort.: Ortalama; TKDD: Tarla kapasitesi su doygunluk derecesi; kg/da: Kilogram/dekar; Aynı harfler aynı grupları göstermektedir.

\section{Teşekkür}


Bu makalede yer alan veriler, DÜBAP13-ZF-30 no'lu "Pamukta Su Stresinin Fizyolojik Bazı Parametreler ile İncelenmesi" konulu projeye ait Sonuç Raporu'nun bir bölümünden elde edilmiştir. Belirtilen projenin finansal desteğini (bütçesi) sağlayan DÜBAP'a teşekkürlerimizi sunarız.

\section{Kaynakça}

Anonim, (2015). Meteoroloji 15. Bölge Müdürlüğü verileri, Diyarbakır.

Awasthi, A., Reddy, K.R., Saha, S. Jenkins, J.N., Stelly, D. M. (2018). Morph-physiological responses of cotton interspecific chromosome substitution lines to low temperature and drought stresses. Euphytica (2018) 214, 218.

Bahramloo, R., Nasseri, A. (2019). Water Use Efficiency and Water Production Function of Corn under Full and Deficit Irrigation in a Cold Semi-arid Environment. Yüzüncü Y1l Üniversitesi Tarım Bilimleri Dergisi Cilt 29, Sayı 2, 213-224.

Bat, M., Tunçtürk, R, Tunçtürk, M. (2019). Kuraklık Stresi Altındaki Ekinezya (Echinacea purpurea L.)' da Deniz Yosununun Büyüme Parametreleri, Toplam Fenolik ve Antioksidan Madde Üzerine Etkisi. Yüzüncü Y11 Üniversitesi Tarım Bilimleri Dergisi Cilt 29, Sayı 3, 496-505.

Benedict, C.R. (1984). Physiology. pp. 189-191. In R.J. Kohel and C.F. Lewis, eds. Cotton. American Society of Agronomy, Inc., Crop Science Society of America, Inc., Soil Science Society of America, Inc., Madison, Wisc.

Beyce, Ö., Madanoglu K., \& Ayla Ç. (1972). Türkiye'de Yetiştirilen Bazı Sulanır Mahsullerin Su Istihlakleri. Merkez Toprak-Su Araştırma Enstitüsü Yayınları Gn. Yayın No:15, Teknik yayın No:12 Ankara.

Cave, J. (2013). Cotton lint yield, fiber quality, and water-use efficiency as influenced by cultivar and irrigation level. Master of Sciences, Texas Tech University, USA. P 192.

Chen, E., Zhang, X., Yang, Z., Zhang, C., Wang, X., Ge, X., \& Li, F. (2019). BR deficiency causes increased sensitivity to drought and yield penalty in cotton. BMC Plant Biol 19, 220.

Davies, W. J., \& Zhang, J. (1991). Root signal sand the regulation of growth and development of plants in drying soil. Annu. Rev. Plant Physiol. Plant mol. Biol. 42, 55-76.

Ekinci, R., Başbağ, S., Karademir, E., \& Karademir, Ç. (2017). The effects of high temperature stress on some agronomic characters in cotton. Pak. J. Bot., 49(2), 503-508,

El-Zik, K. M., \& Thaxton, P. M. (1989). Genetic Improvement for Resistance to Pests and Stresses in Cotton. In Integrated Pest Management Systems and Cotton Production. John Wiley and Sons. New York.

Gerik, TJ., Faver, KL, Thaxton, PM, \& El-Zik, KM. (1996). Late-season water stress in cotton: I. Plant growth, water use, and yield. Crop Sci 36, 914-921.

Hasan, M.M., Ma, F., Islam, F., Sajid, M., Prodhan, Z.H., Li, F., Shen, H., Chen, Y., \& Wang, X. (2019). Comparative Transcriptomic Analysis of Biological Process and Key Pathway in Three Cotton (Gossypium spp.) Species Under Drought Stress, Int. J. Mol. Sci. 20, 2076;

Heitholt, J.J. (1994). Canopy characteristics associated with deficient and excessive cotton plant population densities. Crop Sci. 34, 1291-1297.

Hussein, F., Janat, M., \& Yakoub, A. (2011). Assessment of yield and water use efficiency of dripirrigated cotton (Gossypium hirsutum L.) as affected by deficit irrigation. Exp. Agri., 9 (1), 121128. Israel.

Ibrahim, W., Zhu, Y., Chen, Y., Qiu, C., Zhu, S., \& Wu, F. (2019). Genotypic differences in leaf secondary metabolism, plant hormones and yield under alone and combined stress of drought and salinity in cotton genotypes. Physiol Plantarum, 165, 343-355.

Idso, S.B., Jackson, R.D., \& Reginato, R.J. (1977). Remote sensing of crop yields. Science 196, 19-25.

Jackson, R.D. (1982). Canopy Temperature and Crop Water Stress. P 43-85. In: D. Hillel (ed). Advances in irrigation, vol. 1. Academic press, New York.

Kaçar, M.M. (2007). Farkll su ve gübre sistemlerinin pamuk bitkisinde su stres indeksinin değişiminin incelenmesi. Çukurova Üniversitesi Fen Bilimleri Enstitüsü Tarımsal Yapılar ve Sulama Anabilim Dalı. Yüksek Lisans Tezi Adana.

Kerby, T.A., Bourland, F.M., \& Hake, K.D. (2010). Physiological rationales in plant monitoring and mapping. In Physiology of Cotton; Stewart, J.M., Oosterhuis, D., MHeitholt, J.J., Mauney, J.R., Eds.; Springer Science \& Business Media: New York, NY, USA, 2010; pp. 304-317. 
Lei, Z.Y., Han, J.M., Yi, X.P., Zhang, W. F., \& Zhanget, Y.L. (2018). Photosynthetica 56, 1326.

Monti, L.M. (1987). Breeding Plants for Drought Resistance: the Problem and Its Relevance. Pages 18 in L. Montiand E. Porceddu, eds. Drought resistance in plants. Physiological and genetic aspects, CEC Publ. EUR 10700 EN. Luxembourg.

Naqvi, S.S.M. (1995). Plant/Crop Hormones Under Stress Ful Conditions. In: Pessarakli, M. (Ed.), Handbook of Plant and Crop Physiology. New York, Basel, Hong Kong. Marcel Dekker, pp: 645-660.

Niu, J., Zhang, S., Liu, S., Ma, H., Chen, J., Shen, Q., Ge, C., Zhang, X., Pang, C., \& Zhao, X. (2018). The compensation effects of physiology and yield in cotton after drought stress, Journal of Plant Physiology, Volumes 224-225,

Pettigrew, W.T. 2004. Physiological consequences of moisture deficit stress in cotton. Crop Sci 44, $1265-1272$.

Quisenberry, J. E., Roark, B., McMichael, \& B. L. (1982). Use of transpiration decline curves to identify drought-tolerant cotton germplasm. Crop. Sci. 22, 918-922.

Radin, J. W., Reaves, L. L., Mauney, J. R., \& French, O. F. (1992). Yield enhancement in cotton by frequent irrigations during fruiting. Agron. J. 84, 551-557.

Ramamoorthy, P.K., Lakshmanan, H.D., Upadhyaya, V., Vadez, \& R.K., Varshney. (2017). Root Traits Confer Grain Yield Advantages under Terminal Drought in Chickpea (Cicer Arietinum L.) Field Crops Res., 201 (2017), pp. 146-161

Singh, B, Norvell, E, Wijewardana, C, Wallace, T, Chastain, D, Reddy, K.R. (2018). Assessing morphological characteristics of elite cotton lines from different breeding programmes for low temperature and drought tolerance. J Agro Crop Sci. 204, 467- 476.

Snowden, C., Ritchie, G., Cave, J., Keeling, W., \& Rajan, N. (2013). Multiple irrigation levels affect boll distribution, yield, and fiber micronaire in cotton. Agron J 105, 1536-1544.

Tarakçığlu, I. (2008). Organik Pamuk ve Tekstil Sanayi. İstanbul Ticaret Odası Yayınları Yayın No: 2008-7. İstanbul.

Topcu, T., Yavuz, I., Bleda, E. A., \& Altun, Z. (2012). Generation of a broad banduv continuum in high order harmonic generation by spatially in homogeneous fields. Physical Review A, 85(1), 013416.

Türkeş, M., Sümer, U. M., \& Çetiner, G. (2000). Küresel İklim Değişikliği ve Olası Etkileri, Çevre Bakanlığı, Birleşmiş Milletler İklim Değişikliği Çerçeve Sözleşmesi Seminer Notları (13 Nisan 2000, İstanbul Sanayi Odas1), 7-24, ÇKÖK Gn. Md., Ankara.

Tüzüner, A. (1990). Toprak ve Su Analiz Laboratuvarları El Kitabı. Köy Hizmetleri Genel Müdürlüğü.

Ullah, A., Sun, H., Yang, X., \& Zhang, X. (2017). Drought coping strategies in cotton: increased crop per drop. Plant Biotech $J 15,271-284$.

Wang, R., Ji, S., Zhang, P., Meng, Y., Wang, Y., Chen, B., \& Zhou, Z. (2016). Drought effects on cotton yield and fiber quality on different fruiting branches. Crop Sci 56, 1265-1276. 